EXTENDED REPORT

\title{
Hepatitis B vaccination in children with juvenile idiopathic arthritis
}

\author{
Ö Kasapçopur, F Çullu, A Kamburoðlu-Goksel, H Çam, E Akdenizli, S Çalýkan, L Sever, N Arýsoy
}

Ann Rheum Dis 2004;63:1128-1130. doi: 10.1136/ard.2003.013201

See end of article for authors' affiliations

Correspondence to

Associate Professor Ozgur

Kasapçopur, Ataköy 4 ,

Kýsým O-117/4 Istanbul

Turkey; ozgurcopur@

e-kolay.net

Accepted

28 September 2003

\begin{abstract}
Objectives: To evaluate the responsiveness of children with juvenile idiopathic arthritis (JIA) to hepatitis $B$ vaccination and to determine the most useful vaccination schedule.

Methods: 39 children with JIA were enrolled in the study; all were in remission and negative to serological testing for hepatitis B surface antigen ( $\mathrm{Hbs} A \mathrm{~g})$. The control group consisted of 41 healthy children. There were two different vaccination schedules: group I was vaccinated at 0,1 , and 3 months; group II was vaccinated at 0,1 , and 6 months. Positive responsiveness to the vaccine was defined as an anti-hepatitis $B$ antibody titre above $10 \mathrm{mlU} / \mathrm{ml}$.

Results: All the children except one with systemic JIA developed an antibody response. None of the JIA patients experienced a flare up or clinical deterioration related to the vaccination. The antibody levels in children with JIA were significantly lower than in the healthy controls. Comparison of the antibody levels between the two vaccination schedules showed no statistical difference in the controls; in the JIA subjects the group II schedule resulted in a trend to a greater response than the group I schedule $(p<0.07)$. Vaccine responsiveness was not influenced by either methotrexate or prednisolone treatment.

Conclusions: Children with JIA had an adequate response to hepatitis $B$ vaccination and the response was not affected by immunosuppressive treatment. A vaccination schedule at 0,1 , and 6 months seems to be preferable to 0,1 , and 3 months.
\end{abstract}

$\mathrm{H}$ epatitis B virus (HBV) infection is endemic in developing countries and is still an important public health problem. ${ }^{1}$ Control measures for HBV infection, especially in chronic diseases of childhood, are of great concern..$^{1-3}$ Owing to variation in immunocompetence in juvenile idiopathic arthritis (JIA) —one of the most important chronic diseases of childhood-there is still no agreement on standard precautions against HBV infection. ${ }^{45}$ Published reports provide inadequate data on this issue. In patients with JIA, effective drug treatment suppresses the immune system and the immunological response. Appropriate vaccination schedules and the responses to vaccines in immunosuppressed children remain to be determined. There have been few studies on this subject. ${ }^{4-7}$

Although it was once believed that hepatitis B vaccination could exacerbate chronic rheumatological diseases in adults, a recent study showed that there is an effective immunological response after hepatitis $\mathrm{B}$ vaccination in these patients. ${ }^{8-10}$

Our aim in this study was to evaluate the responsiveness to hepatitis B vaccination of children with JIA and to determine the most useful vaccination schedule.

\section{METHODS}

Thirty nine children (21 male, 18 female) with JIA-all fulfilling the 1997 ILAR diagnostic criteria ${ }^{11}$-were included in the study. All children with JIA ( 11 with systemic JIA, 11 with oligoarticular JIA, 10 with polyarticular JIA, and seven with enthesitis related arthritis) were in remission and had CHAQ scores of less than 0.5..$^{12}$ The duration of disease in children with JIA was at least six months. Forty one healthy children (21 female, 20 male) served as the control group. This healthy group consisted of children attending a well child outpatient clinic who had not previously been vaccinated with hepatitis $B$ vaccine.

The parents were asked whether the children had been vaccinated against hepatitis B. Hepatitis B surface antigen
(HBsAg) and hepatitis B antibody (anti-HBs) values of all non- vaccinated children were determined. Children with negative HBsAg and negative anti-HBs were included in the study. Informed consent, approved by our ethics committee, was obtained at the time of the first visit.

Some demographic characteristics of the subjects are shown at table 1 . The children with JIA were subgrouped on the basis of disease subtype as well as on whether they were receiving corticosteroids or methotrexate. At the time of the study, 10 male and 10 female patients (mean age 10.41 years (range 5 to 16)) were taking corticosteroids. Daily mean prednisolone dose was $6.05 \mathrm{mg}$ (range 2.5 to $10 \mathrm{mg} /$ day). Nineteen patients with JIA ( 11 male, eight female) were not taking corticosteroids. Their mean age was 9.87 years (range 4 to 16$)$.

Twenty two of the JIA group (11 male, 11 female, mean age 9.81 years (range 5 to 15$)$ ) were receiving methotrexate ( $10 \mathrm{mg} / \mathrm{m}^{2} /$ week), while 17 (seven female, 10 male) were not receiving methotrexate (mean age 10.2 years (range 4 to 16)).

\section{Vaccination procedure}

The children were allocated to two groups, given two different vaccination schedules, depending on the order in which they entered the study. The first child with JIA entering the study was put in the first group (group I), the second into the second group (group II), the third into group $\mathrm{I}$, and so on. The healthy control children were grouped in the same way. Group I children were vaccinated at 0,1 , and 3 months; group II children were vaccinated at 0,1 , and 6 months. Children weighing more than $20 \mathrm{~kg}$ were vaccinated with a $20 \mu \mathrm{g}$ dose of DNA recombinant vaccine, while those

Abbreviations: anti-HBs, hepatitis $B$ antibody; $\mathrm{CHAQ}$, childhood health assessment questionnaire; GMT, geometric mean titre; $\mathrm{HbsAg}$, hepatitis $B$ surface antigen; HBV, hepatitis B virus; ILAR, International League of Associations for Rheumatology; JIA, juvenile idiopathic arthritis 


\begin{tabular}{llllll} 
Table 1 & \multicolumn{2}{c}{ Demographic characteristics of the study groups } \\
\hline $\begin{array}{l}\text { Study } \\
\text { group }\end{array}$ & $\mathbf{n}$ & $\begin{array}{l}\text { Female/ } \\
\text { male }\end{array}$ & $\begin{array}{l}\text { Age at investigation } \\
\text { (years) }\end{array}$ & $\begin{array}{l}\text { Duration of disease } \\
\text { (years) }\end{array}$ \\
\hline JIA & 39 & $18 / 21$ & $10.03(3.26), 4$ to 16 & $3.36(2.02), 1$ to 8 \\
$\begin{array}{l}\text { Healthy } \\
\text { controls }\end{array}$ & 41 & $21 / 20$ & $8.8(2.63), 5$ to 14 & - \\
\hline
\end{tabular}

Values are $\mathrm{n}$ or mean (SD), range.

JIA, juvenile idiopathic arthritis.

below $20 \mathrm{~kg}$ were given $10 \mu \mathrm{g}$. Every child in the study group received DNA recombinant vaccine (Engerix $\mathrm{B}^{\circledR}$ ).

\section{Clinical assessment}

The study group was followed up regularly for seven months and the children were seen every month by the same rheumatology specialist (ÖK). During these visits, their clinical status, joints with active arthritis, CHAQ scores, and probable vaccine side effects were determined. The parents received formatted diaries to record side effects. All local (discolouration, swelling, abscess formation, and so on) or systemic side effects (such as fever not related to JIA or dizziness) within 10 days of vaccination were recorded. A complete blood count and erythrocyte sedimentation rate for each child was measured at every visit. Hepatic enzyme levels (alanine transaminase and aspartate transaminase), measured at the start of the study and during the study period, were within normal limits.

\section{Assessment of the humoral response}

Serum samples were collected from each child one month after the end of the immunisation schedule (for group I at 4 months and for group II at 7 months). The serum samples were frozen immediately and stored at $-20^{\circ} \mathrm{C}$ until serological analysis. Concentrations of anti-HBs were measured by enzyme immunoassay (AUSAB EIA, Abbott Laboratories, Chicago, Illinois, USA) and were expressed as mIU/ml. Seroconversion and positive responsiveness to the vaccine were defined as an anti-HBs titre above $10 \mathrm{mIU} / \mathrm{ml}$.

\section{Statistical analysis}

Anti-HBs titres were log-transformed to calculate the geometric mean titres (GMT) and groups were compared by Kruskal-Wallis one way analysis of variance. All statistical analyses were carried out with the SPSS version 10.0 (SPSS Inc, Chicago, Illinois, USA). Probability (p) values of less than 0.05 were considered significant.

\section{RESULTS}

The age distribution of children with JIA was not statistically different from that of the healthy controls (table 1).

\section{Seroconversion rate and vaccine safety}

With the exception of one child with systemic JIA, all the children developed an effective antibody response. The GMT antibody levels in the children with JIA were significantly lower than in the healthy controls. There was no sex difference in vaccine responsiveness, neither was there any significant difference in antibody levels between the subgroups of JIA subjects (table 2). The GMT of the antiHBs concentrations was $134.2 \mathrm{mIU} / \mathrm{ml}$ in patients with oligoarticular JIA, $122.2 \mathrm{mIU} / \mathrm{ml}$ in patients with polyarticular JIA, $135.91 \mathrm{mIU} / \mathrm{ml}$ in patients with systemic JIA, and $93.1 \mathrm{mIU} / \mathrm{ml}$ in patients with enthesitis related arthritis.

The 12 year old boy with systemic JIA who did not respond to the vaccine had a disease duration of 5.5 years and was vaccinated following the first vaccination schedule. During the vaccination procedure he was receiving $5 \mathrm{mg} / \mathrm{day}$ of prednisolone and $10 \mathrm{mg} /$ week of methotrexate. After receiving two booster doses of hepatitis B vaccine with a one month interval, he finally developed a positive response to the vaccine.

\section{Schedule comparison}

In the healthy controls, no significant difference was found between the antibody levels in the two vaccination schedule groups. In the JIA subjects there was a trend to greater responsiveness in group II compared with group I. This just failed to achieve statistical significance $(p=0.07)$.

\section{Effect of drug treatment}

The vaccine responsiveness was not influenced by either methotrexate or prednisolone treatment. The GMT of patients who were receiving these drugs was no different from that of children not receiving immunosuppressant treatment: prednisolone, GMT $109.7 \mathrm{IU} / \mathrm{ml}(\mathrm{n}=20)$; not on prednisolone, GMT $141.05 \mathrm{IU} / \mathrm{ml}(\mathrm{n}=19)$; methotrexate, GMT $114.4 \mathrm{IU} / \mathrm{ml}(\mathrm{n}=22)$; not on methotrexate, GMT 137 $\mathrm{IU} / \mathrm{ml}(\mathrm{n}=17)$. There was a non-significant negative correlation between prednisolone dose and anti-HBs titre $(r=-0.23, \mathrm{p}=0.17)$.

\section{Clinical exacerbation}

None of the JIA patients experienced a flare up or clinical deterioration related to the vaccination. The CHAQ values of patients before and after vaccination periods were not different.

\section{Side effects}

None of the children showed any side effects from hepatitis B vaccine.

\section{DISCUSSION}

The relations between different vaccination schedules in children with chronic rheumatological diseases and the antibody responses of such patients when receiving immunosuppressive treatment are still not clear.4679 To our knowledge, there have been only two studies (of influenza vaccine) in children with chronic rheumatological disease. In both those studies, which had no control groups, the children had an effective antibody response to split vaccination. ${ }^{67}$

Data from some case reports have shown that hepatitis B vaccination may trigger different autoimmune diseases. ${ }^{8} 9$ This is the reason for the lack of large studies of hepatitis B vaccination in children with chronic rheumatological diseases. The only published study was by Davies and Woo. ${ }^{4}$ The British Society of Rheumatology recommended that a standard hepatitis $B$ vaccination schedule with a

Table 2 Vaccination results

\begin{tabular}{lllll}
\hline Study group & Seroprotection & Anti-HBs level (GMT) & Group I anti-HBs GMT & Group II anti-HBs GMT \\
\hline JIA & $38 / 39$ & $137.4 \mathrm{IU} / \mathrm{ml}$ & $88.4 \mathrm{IU} / \mathrm{ml}(\mathrm{n}=19)$ & $207 \mathrm{mlU} / \mathrm{ml}(\mathrm{n}=20)$ \\
Healthy controls & $41 / 41$ & $258.93 \mathrm{mlU} / \mathrm{ml}$ & $226.3 \mathrm{mlU} / \mathrm{ml}(\mathrm{n}=20)$ & $281.7 \mathrm{mlU} / \mathrm{ml}(\mathrm{n}=20)$ \\
\hline
\end{tabular}


booster dose would give a sufficient antibody response. In our study, we showed that an effective antibody response can be achieved in the great majority of cases without booster doses.

A study by Elkayam et al showed that 15 of 22 adults with rheumatoid arthritis $(68 \%)$ responded to hepatitis B vaccine. ${ }^{10}$ In our study population, entirely consisting of children, $97 \%$ of patients responded to the vaccine and did not need a booster dose. The antibody response was not affected by the disease subtype.

An important question is to determine the most effective vaccination schedule. One previous study showed that vaccination at 0,1 , and 6 months was effective. ${ }^{14}$ In our study, this schedule also appeared to be more effective than one involving vaccination at 0,1 , and 3 months.

Vaccination programmes in patients with chronic rheumatological diseases are not reported to cause any side effects or disease flare-ups. ${ }^{67}$ None of the children in remission in our study showed clinical deterioration or relapse.

As in other studies, ours showed that the antibody response to vaccination was not affected by prednisolone or methotrexate treatment, possibly because of various processes affecting immunological responsiveness. ${ }^{6}{ }^{7}$ In addition, hepatitis $\mathrm{B}$ vaccination did not cause deterioration of the primary disease or activation of arthritis in patients with JIA. The answer to the question posed by Sibilia and Maillefert ${ }^{5}$ : "Induction of rheumatoid arthritis by vaccination against hepatitis B: myth or reality?" should be "myth."

The power of our study to detect differences in antibody responses was limited by the small size of the study population and by the fact that the clinical investigators were not blinded to the clinical status and the allocation of the patients to individual subgroups. Our other limitation was that only patients in remission were included in the study. Thus we could not determine whether antibody responses are adequate in patients with active disease. Another unanswered question is whether the response to the vaccine is protective or not. Our data need to be confirmed in a larger study with groups including patients with active disease.

\section{Conclusions}

Children with JIA gave an adequate response to hepatitis B vaccination, and the response was not affected by immunosuppressive treatment. A vaccination schedule at 0, 1, and
6 months appeared to be the most effective. Further studies are needed with larger numbers of patients to confirm these findings.

\section{ACKNOWLEDGEMENTS}

This work was supported by the Research Fund of the University of Istanbul, project number NR B-699/10082000.

\section{Authors' affiliations}

Ö Kasapçopur, F Çullu, A Kamburoðlu-Goksel, H Çam, E Akdenizli, S Çalýkan, L Sever, N Arýsoy, Departments of Paediatrics, Cerrahpaa Medical Faculty, Istanbul University, Istanbul, Turkey

\section{REFERENCES}

1 World Health Organisation. Towards the elimination of hepatitis B: a guide to the implementation of national immunization programs in the developing world. Geneva: WHO, 2001.

2 Kane M. Global program for control of hepatitis B infection. Vaccine 1995; 13(suppl 1):S47-9.

3 Lemon SM, Thomas DL. Vaccines to prevent viral hepatitis. N Engl J Med 1997:336:196-204

4 Davies K, Woo P. Immunization in rheumatic diseases of childhood: an audit of the clinical practice of British paediatric rheumatology group members and a review of the evidence. Rheumatology 2002;41:937-41.

5 Sibilia J, Maillefert JF. Vaccination and rheumatoid arthritis. Ann Rheum Dis 2002;61:575-6.

6 Malleson PN, Tekano JL, Scheifele DW, Weber JM. Influenza immunization in children with chronic arthritis: a prospective study. J Rheumatol 1993;20:1769-73.

7 Kanakoudi-Tsakalidou F, Trachana M, Pratsidou-Gertsi P, Tsitsami E, Kyriazopoulou-Dalaina V. Influenza vaccination in children with chronic rheumatic diseases and long-term immunosuppressive therapy. Clin Exp Rheumatol 2001;19:589-94.

8 Maillefert JF, Sibilia J, Toussirot E, Vignon E, Eschard JP, Lorcerie B, et al. Rheumatic disorders after hepatitis $B$ vaccination. Rheumatology (Oxf) 1999;38:978-83.

9 Avery RK. Vaccination of the immunosuppressed adult patients with rheumatological disease. Rheumatol Dis Clin North Am 1999;25:567-84

10 Elkayam O, Yaron M, Caspi D. Safety and efficacy of vaccination against hepatitis $B$ in with rheumatoid arthritis. Ann Rheum Dis 2002:61:623-5.

11 Petty RE, Southwood T, Baum J, et al. Revision of the proposal classification criteria for juvenile idiopathic arthritis; 1997. J Rheumatol 1998;25:1991-4.

12 Giannini EH, Ruperto N, Ravelli A, Lovell DJ, Felson DT, Martini A. Preliminary definition of improvement in juvenile arthritis. Arthritis Rheum 1997;40:1202-9.

13 Özdŏgnn H, Ruperto N, Kasapçopur Ö, et al. The Turkish version of childhood health assessment questionnaire (CHAQ) and the child health questionnaire. Clin Exp Rheumato 2001;19(suppl 4):S158-62.

14 Halsey NA, Moulton LH, O’Donovan JC, et al. Hepatitis B vaccine administered to children and adolescents at yearly intervals. Pediatrics 1999;103:1243-7. 